\title{
DETRÁS DE LOS MANDATOS Y LA MINGA INDÍGENA: ENTRE ACTOS Y PALABRAS... -PROFUNDAS RAZONES- MAYORES PROPÓSITOS (UN ENCUENTRO CON UNA FORMA DE ACCIÓN COLECTIVA)
}

\author{
BEHIND THE MANDATES AND THE INDIGENOUS MINGA: AMONG ACTIONS \\ AND WORDS... DEEP REASONS - MAJOR COMMITMENTS \\ (A MEETING WITH A FORM OF COLLECTIVE ACTION)
}

\author{
John Gregory Belalcázar Valencia'
}

\begin{abstract}
RESUMEN
La tesis del presente documento gira en torno a reconocer aquello que está contenido en la expresión de la minga indígena y sus mandatos, que como fenómeno sociocultural y político resulta ser una realidad social y cultural portadora de hechos, discursos y contenidos simbólicos que configuran el sentido mismo de la acción colectiva como lugar de resistencias. El acercamiento que interesa al presente ensayo es el centro mismo del acto manifiesto y la palabra dicha, entendiendo la acción colectiva como un devenir de lugares de relaciones e interacciones sociales afirmativas. En su propósito de comprender antes que explicar, el documento inicia reconociendo un antecedente histórico que ha marcado estos procesos de resistencia indígena en el norte del cauca y en Colombia; luego se expone un concepto previo que consiste en desarrollar ideas que tienen el propósito de adentrarnos en lo que representa desde las comunidades indígenas sus actos, sus palabras y su propia realidad para que pueda ser tocada, sentida y respirada. El ejercicio comprensivo se sustenta en un análisis del discurso sobre los mandatos indígenas, para evidenciar a través de ellos cómo los movimientos sociales indígenas han significado una búsqueda de lo colectivo y una afirmación como pueblo y organización.
\end{abstract}

Palabras clave: Acción colectiva, identidad, Minga, Resistencia, subjetividad.

\section{ABSTRACT}

The thesis of the present document turns around the recognition of which is contained in the expression of the Indigenous Minga and its mandates as a sociocultural and political phenomenon carrier of events, speeches and symbolic content which shape their collective action as a place of resistance. The approach in which this essay is interested is the center itself of the overt act and the spoken word, understanding the collective action as affirmative and social relations and interactions. In its aim of understanding rather than explaining, the document begins by acknowledging a historical precedent that has marked these processes of indigenous resistance in the north of Cauca in Colombia. Then a previous concept is outlined in order to develop intended ideas to get into indigenous communities through their actions and words, showing

1 John Gregory Belalcázar Valencia: Tutor de la Escuela de Ciencias Sociales, Artes y Humanidades de la Universidad Nacional Abierta y a Distancia, CEAD Palmira, Colombia. Correo electrónico: jgbelalcazar@yahoo.com 
how their own reality may be touched, felt and breathed. The comprehensive exercise is based on an analysis of indigenous discourse about their mandates, to show through them indigenous social movements have meant a search for the collective world and so an assertion as the people and its organization.

Key words: Collective action, identity, Minga, resistance, subjectivity.

Recibido: 30 de agosto de 2011 Aceptado: 21 de noviembre de 2011

\section{INTRODUCCIÓN}

No hay un ensayo sin tesis o, por lo menos sin un mínimo de reflexión básica que permita movilizar ideas y provocar pensamientos. Así, la tesis del presente ensayo se sitúa en la comprensión del hecho de potenciar la voz de otro e incluso la propia, desde la acción de un movimiento social que indica un lugar de resistencias contra la sujeción /sumisión de la subjetividad. En ese principio se procura reconocer un movimiento social como la minga indígena, que representa en esencia un escenario de pactos intersubjetivos mediados por la elaboración simbólica sustentada en el acto de decir y en la palabra que expresa un lugar de resistencias. Con la palabra se expone un narrar procesos subjetivos individuales y sociales ocurridos al principio de la reafirmación de identidad como pueblo y como organización en acción colectiva. Es significativo señalar que el presente ensayo gira en torno a las cuestiones agrarias y las dinámicas de las comunidades indígenas norte-caucanas en Colombia. Sus voces continúan dejando desde hace largo tiempo manifestaciones que han dejado evidenciar un proceso organizativo de orden social, político, económico y cultural que sustentan la esencia misma del pueblo y la comunidad, dándole sentido a lo étnico como espíritu ordenador de la razón misma de ser sujeto-comunidad. Se trata de un yo, un nosotros que se reafirma frente al otro, entendido como el resto de la sociedad, el Estado mismo ante los cuales plantea su situación y desarrolla su acción social y política.

\section{Trazando un mapa para un viaje comprensivo}

El ejercicio propuesto expone la necesidad de configurar un mapa que trace rutas (temas), movilice ideas (perspectivas conceptuales emergentes al considerar esos temas) y acoja posibilidades (el singular acto de problematizar desde esos temas). En tales condiciones, el área problemática se ubica dentro de los estudios del comportamiento colectivo, concretamente, de los movimientos sociales, en aquellos aspectos que se refieren a la producción simbólica, la creación de procesos de significación social y la construcción de subjetividad social. Esta última está presente durante la acción colectiva, creando cosmovisiones e imaginarios alternativos a los que circulan en la cultura cotidiana y teniendo como marco, la biopolítica y la gubernamentalidad.

Para pensar la minga y el mandato... como intención. Este fenómeno de la minga indígena ha representado un impacto en 
el imaginario colectivo (representaciones sociales que se tenían de los indígenas) a nivel nacional, al exponer una lógica de capacidad organizativa que hace visible y emergente a un sujeto colectivo, a una comunidad étnica. Por otro lado, su presencia como acto simbólico ha modificado el modo de conocer esta comunidad y relacionarnos con ella, y a la vez ha producido profundos cambios psicosociales y fenómenos psicopolíticos de nuestro interés. Específicamente dejan entrever su papel como actor-creador de procesos de significación social en los escenarios colombiano e internacional, relacionados con la construcción y ejercicio de la ciudadanía.

Considerando la resistencia indígena, "los imaginarios y representaciones en torno a la invención de las naciones, la ilusión de homogeneidad y las estrategias para producir los sujetos modernos de la nación y el ciudadano, han encontrado en la cuestión de lo étnico y de las relaciones interétnicas un punto de referencia crucial" (Foucault, 1991), lo que hace pensar que aquellos procesos de significación social se configuran en torno a la apuesta que una comunidad ha planteado por un proyecto colectivo puesto en escena bajo dos mandatos: El Mandato: Libertad para la madre tierra (Tabla 1) y El Mandato indígena y popular de la minga por la vida, la justicia, la alegría, la libertad y la autonomía (Tabla 2).
Tabla 1

Mandato: Libertad para la madre tierra.

"Hay una razón profunda que inspira nuestros actos y palabras. Hay un propósito mayor que orienta nuestra lucha. Somos del Cauca y desde el Cauca somos de la vida y para ella. Estas palabras explican y reclaman; por eso hay que leerlas desde el corazón y compartir la rabia, el dolor, el amor por la vida y el compromiso. Ahora nombramos nuestros actos para sentir y reclamar la compañía de todos los pueblos que merecemos habitar este hogar de la madre tierra en libertad. (...) Los pueblos indígenas sabemos, desde una memoria más profunda, desde nuestras historias más antiguas, desde nuestras experiencias diversas, desde los recuerdos y preceptos que están inscritos en nuestras lenguas, desde nuestros usos y costumbres y sobre todo desde el dolor, el maltrato y la incomprensión, que la historia desde la conquista, la historia del capital y de quienes a su nombre lo acumulan, es un proyecto de muerte que terminará por destruir la naturaleza toda, incluida la vida de los seres humanos. Para nosotros, la tierra es la madre. Contra ella se comete un crimen del que vienen todos los males y miserias. Nuestra madre todos los seres vivos, está sometida, según la ley que se impone, tiene dueños, es propiedad privada. Al someterla como propiedad para explotarla, le quitaron la libertad de engendrar vida y de proteger $y$ enseñar el lugar, las relaciones y el tiempo de todo lo que vive. (...) Pero nosotros decimos, mientras sigamos siendo indígenas, o sea, hijos de la tierra, que nuestra madre no es libre para la vida, que lo será cuando vuelva a ser suelo y hogar colectivo de los pueblos que la cuidan, la respetan y viven con ella y mientras no sea así, tampoco somos libres sus hijos". 
Tabla 2

Mandato Indígena y popular de la minga
por la vida, la justicia, la alegría, la
libertad y la autonomía.
"EL DESAFío QUE NOS CONVOCA: Con
nosotros vienen los recuerdos y las
experiencias de una larga historia de lucha
y de resistencia. Echamos mano de nuestras
identidades y de nuestras culturas para
enfrentar las amenazas que ha traído cada
época. Este camino no ha sido fácil. Desde
la conquista y sin descanso, la arrogancia,
el egoísmo, la ignorancia y el irrespeto,
disfrazados de distintas maneras, han caído
sobre nosotros con engaños y mentiras,
con falsas promesas, con el poder de armas
cada vez más sofisticadas y mortales y con
instituciones, normas y leyes que nos traen
miseria, explotación, dolor y sometimiento.
Cada vez quelleganaatropellarnos, aseguran
que es por nuestro bien. En cada época
hemos tenido que descubrir el engaño,
unirnos y organizarnos para defendernos.
Siempre nos sirvió volver a las raíces, echar
mano de la sabiduría contenida en ellas,
de la memoria colectiva, escuchar a los
mayores y acercarnos a la naturaleza para
hacernos parte de la vida toda y defendernos
defendiéndola. En cada época tuvimos que
aprender a resistir y hacerlo de una manera
diferente de acuerdo con el desafío que
enfrentamos. Venimosmarchando desdelejos,
desde hace mucho tiempo, por el camino de la
historia. Los últimos pasos que nos trajeron a
este Congreso ltinerante de los Pueblos, son
la etapa más reciente de esa larga historia,
pero también establecen el comienzo de un
nuevo camino que hemos decidido recorrer"

Ante una comunidad que se narra, se expone como eje central la identidad como problema, en la cual se reconocen tres características (Melucci, 2001). Según él, existe un rasgo diferenciador como fenómeno, marcado desde la esencia de un marco espacio-temporal (un espacio geográfico, uno antropológico, uno vital que es el lugar de anclaje de su identidad). Un segundo rasgo se expresa en la dinámica subjetiva-intersubjetiva, consistente en que la intensidad de los contenidos significa una experiencia trascendente para el sujeto colectivo (memoria individual y colectiva), fenomenológicamente el ser siendo. Un tercer rasgo lo definiría consecuentemente la evidencia de una acción simbólica que trasciende el simple encadenamiento de los hechos por medio de un juego de articulaciones simbólicas (el mito fundante) que define el contenido y el sentido de la acción misma.

La minga, hecho excepcional... un acto discursivo y simbólico. Un fenómeno social como el de los mandatos y la minga indígena que se plantean como acontecimientos excepcionales, rompen lo rutinario y se salen de esa marca habitual y cotidiana de lo acostumbrado -lo naturalizado-, al dinamizar un flujo relacional que inciden en el imaginario colectivo -un reconocerse a sí mismos-, y en la forma de percibir la realidad misma -la manera como se define $y$ construye en su sentido. Son hechos sociales que por su particular naturaleza atraen la atención sobre un colectivo que se inventa a sí mismo; sus actos se constituyen en eventos que se cargan de componentes sociales, culturales, políticos y económicos Por esto se considera que "Los movimientos contemporáneos son profetas del presente. Lo que ellos poseen no es la fuerza del aparato, sino el poder de la palabra". Este movimiento social indígena halla y concentra en la palabra lo vital de su acción colectiva, que se expresa en la apuesta por una minga con objetivos para el movimiento indígena hacia adentro y hacia afuera, en su documento "Libertad para la madre tierra":

Objetivos de la minga. Es necesario hacer claridad en algunos aspectos relacionados con los objetivos planteados. Aunque se hacen unas exigencias inmediatas, estas 
son inseparables de los objetivos de largo plazo que se persiguen con la minga. Tener éxito frente a las exigencias urgentes no es el propósito de la minga. En este sentido también es necesario aclarar que con la marcha y con la movilización inicial no termina la minga. Teniendo en cuenta estas aclaraciones, se plantean los siguientes objetivos:

1. Para el Movimiento indígena hacia adentro:

- Convocar una minga que respondiendo a la grave amenaza que representa para la vida de las comunidades indígenas la agresión neoliberal que enfrentamos, nos comprometa con un proceso de formación y lucha que nos lleve a hacer conciencia de la agresión, resistirla y construir alternativas de vida desde lo propio.

2. Desde el Movimiento indígena hacia afuera:

- Plantear exigencias de carácter urgente encaminadas a detener políticas, procesos y proyectos que amenazan la supervivencia y la seguridad de nuestros pueblos, organizaciones y comunidades.

- Establecer instancias y mecanismos de articulación y convergencia con otros procesos y organizaciones populares que nos posibiliten trabajar y actuar unidos para fortalecer la resistencia y construir alternativas que hagan posible un país diferente.

- Fortalecer la solidaridad recíproca con pueblos y procesos de las américas y del mundo que comparten la resistencia y nuestra lucha por un mundo posible $y$ necesario.
La minga y los mandatos son apuestas que buscan sustraerse de lo rutinario (con una historia oficial que lo ha validado) y colocarse en el nivel de la preocupación colectiva (una opinión pública) al poner en juego elementos discursivos que exigen ser negociados bajo un marco simbólico de revalidación o resignificación de lo ya representado e imaginado como elaboración colectiva y que se hallan anclados en la memoria colectiva La minga como acto es la posibilidad de que las comunidades indígenas del norte del Cauca introduzcan elementos discursivos que sacudan lo cotidiano, provoquen un alto, exijan un acercamiento dentro de las dinámicas económicas y políticas propias, a partir de unos mínimos. Se clama por un mundo intersubjetivo donde la relación del sujeto con esa realidad es de carácter social, al tenor de lo que expresa "El Mandato indígena y popular de la minga por la vida, la justicia, la alegría, la libertad y la autonomía":

"La palabra que traemos en paz se ha convertido en hechos que hablan por sí mismos. Los medios comerciales de comunicación, en su mayoría nos escucharon y muchos dejaron de distorsionar la verdad para transmitir nuestras propuestas. La solidaridad del mundo se hizo presente y nos acompañó. Asumimos este reconocimiento y respeto como una responsabilidad colectiva que nos obliga a avanzar por el camino y asumir el desafío que enfrentamos. Este MANDATO recoge lo que viene de atrás y señala lo que vamos a hacer ahora. Dejamos constancia de la forma tendenciosa, irresponsable e irrespetuosa en que el Presidente de la República pretendió impedir la realización de este primer congreso indígena y popular, así como la manera en que mintió recurrentemente sobre los motivos y contenidos del mismo y engañó a la opinión pública nacional e internacional 
describiendo esta iniciativa pacífica, civil y democrática, como un acto politiquero de terroristas".

Esta dinámica relacional a través de la minga como movilidad política, y del mandato como contenido discursivo, es la forma como el individuo experimenta su realidad proveyéndole de un sentido, una intención; sin esa práctica relacional de carácter social, todo elemento y todo sujeto que defina allí una dimensión vital, sería una abstracción particular, aislado del universo simbólico. Sería algo no situado, no temporalizado, ni anclado a una memoria o a un marco simbólico referencial que permita organizarse como conducta manifiesta por parte del sujeto social. Realmente son parte de su proceso de identidad en construcción permanente a través de eventos que terminan legitimando su situación sociocultural y política y la de otros, ese otro que confronta. Así las cosas, tal estaríamos ante un movimiento social que más allá de reivindicar cuestiones agrarias, se funda en la dimensión étnica y cultural contenida en "El Mandato indígena y popular de la minga por la vida, la justicia, la alegría, la libertad y la autonomía", cuando dice:

El desafío que impone esta nueva época es grande. Tal vez el mayor que hayamos tenido que enfrentar en nuestra historia. Nos agrede y sufrimos un orden que está mal, que hace daño y que no sirve, eso lo sabemos y lo decimos con fuerza. No solamente están a riesgo nuestras culturas, nuestras comunidades, nuestros pueblos y familias. Es peor, la vida misma corre el riesgo de ser destruida por la ceguera de quienes se han equivocado y utilizan el mayor poder de la historia para convertir en mercancía todo lo que existe a través de su Proyecto de Muerte. (...)
El Proyecto que amenaza la vida no respeta fronteras, por eso lo llaman globalización. Llega hasta nuestras comunidades y hasta nuestros hogares en todas partes de Colombia y del mundo. Trae la guerra, las mentiras de la propaganda con que engaña con habilidad y todo el poder de las leyes y del dinero. Viene por la riqueza de la naturaleza y por el trabajo de la gente para explotarlos y venderlos como mercancía. Los que lo controlan y toman decisiones para servir sus intereses están lejos. (...) Todo esto es difícil de ver, de entender, de resistir y de cambiar. Nos exige unidad, creatividad, inteligencia, solidaridad, compromiso, sacrificio y mucho trabajo, pero también mucha alegría y muchas ganas de vivir. Precisamente porque enfrentamos un desafío grande y distinto a todos los que nos han tocado hasta ahora, esta movilización es diferente. No salimos solamente a exigir, a reclamarle al Gobierno, a denunciar, aunque también lo vamos a hacer. Esta vez salimos a convocar pueblos, organizaciones y procesos populares.

Si volvemos al hecho excepcional nos encontramos actos discursivos que se inscribendentrodeluniverso cotidiano, pero como prácticas que implican una profunda movilización colectiva que pasa por la concreción (representación - invención) de un sujeto colectivo que construye su sentido de lo social y de lo comunitario y continúa por la mediación del movimiento social indígena como un referente de situación-acción social, cultural y política. El movimiento social indígena posee una dinámica dirigida hacia lo excepcional, que provoca impacto y confronta esa representación que tenemos de "la unidad homogeneizante" en términos de Melluci.

Un ejercicio de lectura de las dinámicas comunitarias que se reconocen en distintos lugares es punto de partida para el trabajo 
de reflexión que aquí se plantea con el movimiento indígena caucano. Es evidente que la nación es un tejido de situaciones entre armonías y tensiones, conflictos y acuerdos, que de alguna forma definen la realidad cotidiana cuestionando así lo aparente. Se propone colectivamente una práctica relacional de orden discusivo que el colectivo indígena toma para sí como una nueva aprehensión de lo ganado con la experiencia, con la necesidad de evaluar la visión de lo que hasta hoy era "mi" realidad en "El Mandato indígena y popular de la minga por la vida, la justicia, la alegría, la libertad y la autonomía":

\begin{abstract}
Marchamos para expresar nuestro compromiso de unirnos y de trabajar tejiendo la solidaridad recíproca que hace falta para defender la vida. Esta vez sabemos que solos no podemos y que nos necesitamos mutuamente para entender, para resistir y para crear un país y un mundo posible y necesario. Hemos sorprendido al Gobierno, al poder, al país y al mundo porque no nos levantamos a pedir lo que es nuestro por derecho propio; en cambio, convocamos esta minga con una propuesta para que entre todos, como pueblos, definamos un mandato indígena y popular que oriente el proceso para que podamos avanzar con pasos firmes y realistas desde esta realidad de confusión y muerte hasta un Proyecto de Vida tejido por nosotros desde los Pueblos.
\end{abstract}

Nuestros actos reivindican el valor de la palabra. Por eso crece nuestro poder de convocatoria y la fuerza de nuestros argumentos. Por nosotros, hablan nuestros actos de dignidad y resistencia que no se detendrán. El primer congreso indígena y popular ha logrado con creces sus objetivos. El país y el mundo nos han escuchado. El Gobierno no pudo ignorarnos y va a tener que respetar la fuerza de nuestra legitimidad
Por todo lo anterior, se constituye esta marcha (que en ningún momento será vista como accidental sino como parte de un proceso que articula procesos previos de corte participativo, principio de una construcción colectiva) en un hecho social complejo que sustrae de lo anónimo sujetos, prácticas, ideas, pensamientos, rituales y lugares que se hallan "situados" dentro un universo colectivo propio. Si reconocemos el movimiento social indígena desde la minga y los mandatos como prácticas sociales situadas, encontramos que el movimiento y la minga tienen el papel vital de las interacciones sociales al interior y al exterior, por la mediación simbólica entre los sujetos y su realidad construida. Mirar la comunidad indígena desde la práctica cotidiana y los hechos sociales excepcionales que promueven, es reconocer muchas dinámicas posibles para la definición de otro; así, la minga y los mandatos son significativamente una mediación que en términos simbólicos se plantea con las representaciones e imaginarios colectivos en "El Mandato indígena y popular de la minga por la vida, la justicia, la alegría, la libertad y la autonomía" en estos términos:

Establecer el Congreso Indígena y Popular con la misión de asumir, abordar y profundizar los temas que convocaron esta gran minga y como escenario para construir y consolidar el proceso hacia el Plan de Resistencia y de Vida de los Pueblos. El Congreso iniciará sesiones en el Territorio De Paz y Convivencia de La María, Piendamó, pero tendrá carácter itinerante y se habilitarán escenarios y espacios de deliberación en todo el territorio nacional de manera que se facilite la participación y liderazgo de todos los procesos populares. Crear un Tribunal Permanente De Los Pueblos con participación de líderes y personalidades de las más altas calidades y capacidades, del nivel nacional e internacional, con la 
misión de examinar, pronunciarse, hacer recomendaciones y tomar acciones frente a los atropellos y violaciones al derecho a la vida y a los derechos humanos de las organizaciones y procesos indígenas y populares. Estableceruna Misión Diplomática PermanenteY Autónoma De Los Pueblos que represente a las Organizaciones y Procesos Populares en gestiones diplomáticas en el ámbito internacional, con representación y mandato desde comisiones Internacionales establecidas al interior de los procesos y movimientos indígenas y populares.

El acto excepcional pone en juego como ejercicio social una pluralidad de escenarios que pasan de lo abstracto (la palabra) al hecho (la marcha, la asamblea) visto aquí como realidad espacio-temporal, hacia una elaboración discursiva donde la propuesta de comunicación del sujeto con su entorno social, no solo será de un simple intercambio de información o transmisión. También incluirá fenómenos no verbales y elaboraciones simbólicas para dimensionarse luego en una realidad espacio-temporal donde se ancla y fundamenta como elaboración colectiva, que se evidencia en "Minga por la vida, la justicia, la alegría, la autonomía y la libertad y movilización contra el proyecto de muerte y por un plan de vida de los pueblos", a través de estas palabras:

Desde nuestro origen somos pueblos de la vida. Nacimos con todos los seres vivos. Nuestros Dioses nos enseñaron a convivir en el territorio para defender el equilibrio y la armonía. Somos pueblos ancestrales y originarios. Los conquistadores trajeron a estas tierras su proyecto de muerte. Vinieron con afán de robarse la riqueza y explotarnos para acumular. El Proyecto de Muerte es la enfermedad del egoísmo que se vuelve odio, guerra, mentiras, propaganda, confusión, corrupción y malos gobiernos. Los pueblos indígenas somos pueblos en resistencia. No nos han dejado descansar.
En cada época de agresión utilizaron estrategias diferentes para exterminarnos o someternos. Siempre nos tocó defendernos empezando por descubrir lo que había detrás de la máscara de mentiras y promesas con las que llegaron a robarnos y matarnos, según ellos "por nuestro bien". Para cada agresión hemos tenido que diseñar otra forma de resistencia. Aquí estamos y aquí nos quedamos. Tuvimos que resistir al conquistador asesino con las armas. En la colonia usamos las letras y la religión para llegar al monarca y obtener reconocimiento para nuestro territorio. En la república impedimos que nos convirtieran en esclavos de terratenientes rescatando primero nuestra conciencia milenaria de indígenas y levantándonos desde el hambre y el dolor para recuperar nuestras tierras. Nos unimos alrededor de una plataforma de lucha sustentada sobre los principios de Unidad, Tierra Y Cultura. Rescatamos la tierra de la gente para la gente. Luego nos comprometimos con avanzar hacia la autonomía a través de la reflexión, la conciencia y la participación para formarnos como gente para la tierra con formas de gobierno e instituciones propias. Pero ahora reconocemos una amenaza mayor y nos corresponde organizarnos para resistirla y pervivir.

Este proceso se ve desde un sujeto social en situación, lo que se plantea como ejercicio de ruptura, interpelación, elaboración o significación de esquemas con una lógica manifestada desde esta práctica relacional discursiva y simbólica que ha sido puesta en juego en su escenario cotidiano propio con políticas agrarias, sociales y económicas que inciden en sus proyectos de vida. Siguiendo la propuesta de Alfonso Ortiz, (conjugada con una idea de Melluci) podríamos distinguir en el acto excepcional tres niveles de realidad: el nivel de los hechos, el de lo discursivo y el de la elaboración simbólica, con "Una conciencia clara de que las posibilidades y limitaciones de la acción 
social pueden transformar la palabra de los movimientos (nivel de los hechos) en lenguaje (nivel de lo discursivo), cultura y relaciones sociales (nivel de lo simbólico), y puede hacer de los procesos colectivos una práctica de libertad". Este acto como prácticarelacional, en la dimensión cognitiva cada sujeto lo piensa, lo representa y lo recuerda como marcos generales de pensamiento y de actividad, ligándolo como imágenes de significación social, a través de pensamientos, sentimientos y actitudes colectivas que expresan la forma de construcción de la realidad bajo un universo social totalizante que los define como sociedad o comunidad.

En esa misma idea, como construcción colectiva(mingaymandatos)eselactosocial que plantea un control al individualismo y direcciona como intención social la compleja simultaneidad de las realidades colectivas que trascienden del imaginar -la comunidad, la nación- hacia procesos históricos que buscan la construcción de los mismos evidenciando la presencia de lugares vitales (geográficos y antropológicos) que son excluidos de la presencia simbólica de fronteras y abismos (procesos de exclusión social, cultural y política) y de escenarios sociales no imaginados, no representados o desapercibidos, en una dimensión cultural que los configura como memoria colectiva. Todo en su conjunto conlleva un soporte al proceso dinamizado como movimiento social (y en cierto sentido el que le define como tal). Cada acto y cada palabra representan la necesidad de una reelaboración, una especie de cartografía social en la que se observen aquellas realidades socioculturales que emergen, que eclosionan un sujeto colectivo, social y político (intersubjetividades movilizadas, subjetividades devenidas). Significaría entonces, que la minga como hecho excepcional por esta particular intencionalidad, eleva el espacio social y cultural a prácticas relacionales que constituyen el fundamento y la confrontación de los universos simbólicos que en apariencia se muestran implícitos y estables. Por ello, es vital considerar que reconocidos como movimiento social, la gente, los sujetos actuantes, no abstraídos desurealidad, sonsujetos situados queviven y elaboran su realidad vital y que participan junto a otros en una continua elaboración de los universos simbólicos desde la puesta en juego de juicios, categorizaciones, estereotipos, sesgos, impresiones, ideas, afectos, tradiciones, etc., las cuales en los sistemas de representación adoptan formas de situación social expresadas así en "Mandato libertad para la madre tierra":

Finalmente, queremos invitar a todos nuestros hermanos que han sido desplazados para que vuelvan a sus tierras, ya es hora de regresar. Pero también invitamos al pueblo colombiano en general, a luchar por la realización efectiva de la reforma agraria, si es que aspiramos algún día, dejar a las próximas generaciones un país más justo, incluyente y equitativo. De lo contrario, muchas guerras y muchos años de sufrimientos seguirán siendo el destino de nuestro pueblo y de todos los pueblos. Reflexionen y advertirán, que muchas violencias, sino es que todas, cuando no han comenzado, han terminado en el campo, en la lucha por la tierra, y la que hoy padecemos, no es la excepción. Ya es hora de superar tanta injusticia y tanto odioso privilegio.

(...) Debemos seguir caminando sobre la huella de nuestros mayores porque hoy nos corresponde dejar un sendero para que nuestros hijos puedan seguir caminando con libertad, el territorio porque la libertad del territorio es el nacimiento de la libertad de los 
pueblos. Convocan a esta gran minga por la vida, la libertad de los territorios y de los pueblos: Comunidades Indígenas Del Cauca y Comisión De Reforma Agraria.

\section{Tres ideas finales como conclusión}

\section{De las cuestiones agrarias y las resistencias como expresión}

Como el propósito es analizar la transformación estructural en la economía agrícola, se hace necesario indicar hacia dónde estarían orientados los propósitos de estas reflexiones y la definición de esos tres momentos, sustentar que lo lógico es tratar las resistencias, como tema que permite ubicar los avances que se quieren establecer aquí, sugiriendo una tesis (provocadora) a la que convoca Foucault (Ver Tabla 3).

Tabla 3

\begin{abstract}
"Me gustaría sugerir otra vía para ir más lejos hacia una nueva economía de las relaciones de poder, una vía más empírica, más directamente relacionada con nuestra situación actual, la cual implica una mayor relación entre la teoría y la práctica. Esta consiste en tomar como punto de partida, las formas de resistencia contra las diferentes formas de poder. Para usar otra metáfora, consiste en usar la resistencia como un catalizador químico que saque a la luz las relaciones de poder, ubique su posición y encuentre sus puntos de aplicaciones y los métodos usados. Más que analizar el poder desde el punto de vista de su racionalidad interna, consiste en analizar relaciones de poder a través del antagonismo de estrategias".

La Organización Nacional Indígena de Colombia, ONIC, comenzó a trabajar con la siguiente plataforma:

1) Defensa de la autonomía indígena.

2) Defensa de los territorios indígenas y recuperación de las tierras usurpadas y la propiedad colectiva de los resguardos.

3) Control de los recursos naturales situados en los territorios indígenas.

4) Impulso a las organizaciones económicas y comunitarias.

5) Defensa de la historia, la cultura y las tradiciones indígenas.

6) Educación bilingüe y bicultural bajo el control de las autoridades indígenas.

7) Recuperación e impulso de la medicina indígena y exigencia de programas de salud acordes con las características sociales y culturales de las comunidades indígenas.

8) Exigir la aplicación de la ley 89 de 1890 y demás disposiciones legales favorables a los indígenas.

9) Solidaridad con las luchas de todos los pueblos explotados y oprimidos.
\end{abstract}

Lo que se logra reconocer aquí (entre la cita de Foucault y los nueve puntos) son los principios ordenadores de una comunidad imaginada a través de la convocatoria de sí, desde la construcción de un imaginario -un nosotros- que se configura como colectivo emergente bajo la reivindicación de una forma de poder social y político fundado sobre lo étnico y lo cultural; una movilidad devenida en el tomar conciencia de la acción colectiva como principio de responsabilidad para sí; un sujeto colectivo -resistencia contra un poder-, otro que valida el sentido de la acción.

Indica el sentido de un nosotros, un ellos que dinamizan procesos de identidad resignificados desde la anunciación de un lugar de reivindicación de poder: el movimiento social indígena. Aquí el problema será entonces reconocer la esencia de una memoria que motiva la definición de nuevas prácticas y nuevos modos de relación que posibiliten la emergencia de un sujeto indígena -con sentido de acción política-, una nueva idea de ciudadanía que se evidencia detrás de dos estrategias que hacen el antagonismo al poder legitimado: Las asambleas (Congreso indígena y popular 2004) y las mingas (marchas indígenas).

El objetivo con esta conclusión (o punto de partida) y desde este eje de discusión-, las resistencias indígenas, imaginadas tras la figura de una movilización del acto de la palabra-, es proponerlo 
como un escenario que quede abierto para considerar las subjetividades como un referente conceptual que contextualice la reflexión sobre lo que representa ese movimiento social.

\section{De los contenidos a los procesos devenidos, desde las resistencias indígenas nortecaucanas}

Es aquí donde se validan los estudios históricos en términos de reconocer sus contenidos, procesos devenidos que sustentan una idea de construcción histórica que nos permitiría comprender los movimientos sociales en "un hoy" como proceso, dándose una vida siempre renovada. Validar como pistas para dejar un rastro comprensivo de estas discusiones (el tema de las reformas, la ruralidad, el sujeto y las ciudadanías) se podría hallar en los conceptos de biopolítica y gubernamentalidad una posibilidad de que estas discusiones se piensen en términos de ese ejercicio continuado, buscando dejar escenarios básicos para el tema de las resistencias de las comunidades indígenas actuales, que merece ser considerado aquí, al observar la tabla 4. El proyecto comunitario se considera como una estrategia de glocalización de la comunidad misma, es decir, lo glocalizado es una acción con sentido para construir la situación-acción desde la comunidad misma. Se convierte en un acto social, cultural, político y económico que hace quiebres a una globalidad emergente.

Tabla 4

\begin{tabular}{|c|c|}
\hline 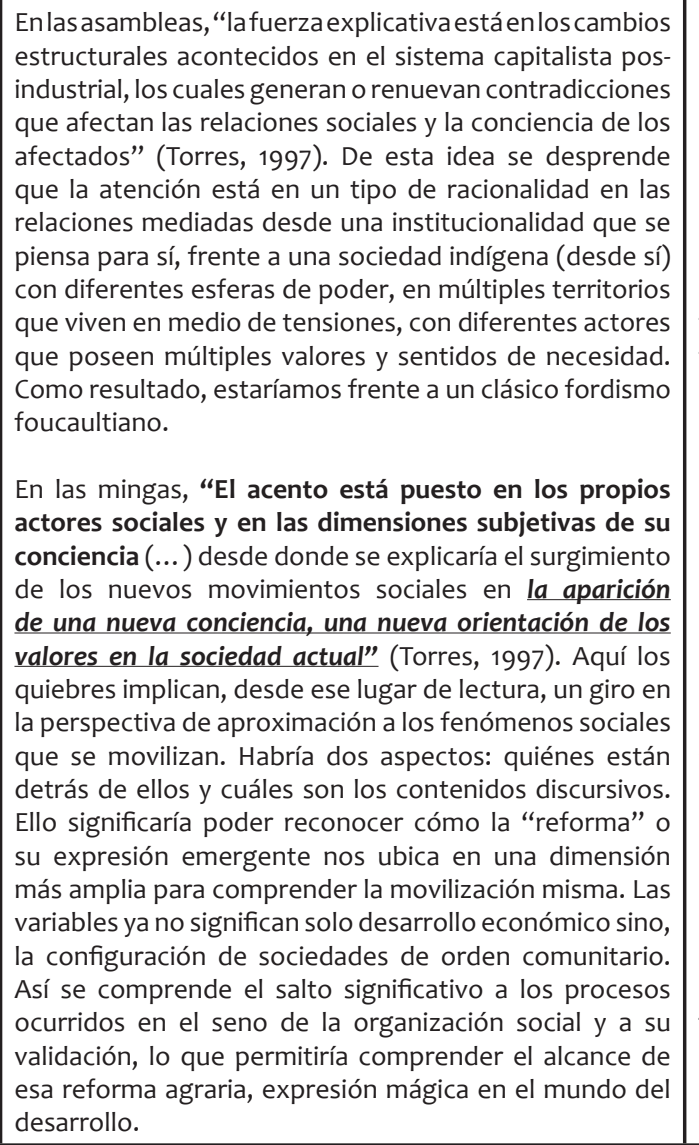 & 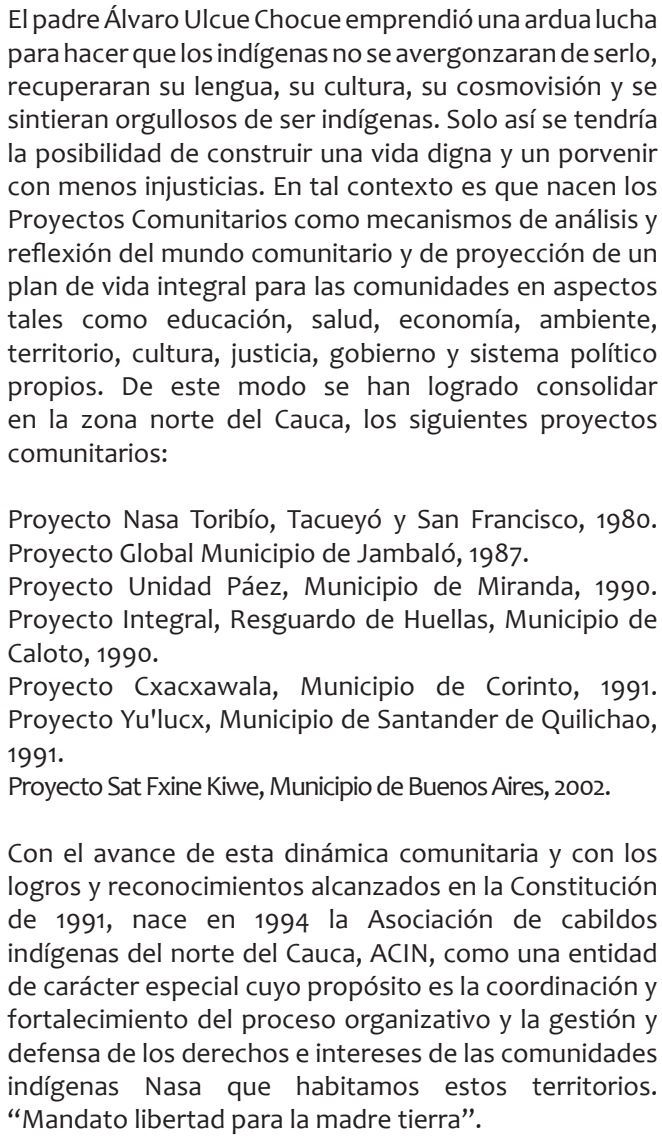 \\
\hline
\end{tabular}




\section{De esa necesidad de decir al decir del sujeto colectivo y la cultura como mediación}

El preguntar por la necesidad de decir y este acto del sujeto son un acto mediado por la cultura. En el caso particular del movimiento indígena, este escenario construye lo que se dice, como se dice y para lo que se dice, tres dimensiones del acto que ya se han observado anteriormente. Ahora, la cultura como texto, como semiótica, representa una posibilidad, antes que una verdad definitiva; es una manera de pensar sobre las inquietudes que rondan las intencionalidades de narrar que tiene el sujeto indígena en una cultura que permite crear un distinto espacio de representación, que pone al individuo en pervivencia desde la cual interpela para surgir como actor social con decisiones visibles, y con el cual, se debe entrar en diálogo. Para ello se requiere previamente entender un fenómeno como el movimiento indígena que tiene sus propias representaciones de lo global, la globalización y el estado-nación, las cuales responden social y culturalmente a las incitaciones de un presente histórico vivido de manera singular en la lógica del relato de un campesino indígena "ilustrado" (ver tabla 5). 
Tabla 5

El Mandato indicaría como principio que: "La importancia de esta teorización para el estudio de la etnicidad reside en que da espacio a un planteamiento que toma en consideración tanto las estructuras de diferenciación étnica como la vivencia subjetiva y la dinámica histórica y social de la etnicidad" (García, 2008). Para incluir lo anterior dentro de una perspectiva de abordaje de los movimientos sociales y de lo nuevo ocurrido en los mismos, habría que considerar los tres puntos de análisis que presenta Ernesto Laclau:

- En primer lugar, la determinación de la identidad de los agentes a través de categorías de la estructura social que los determina a priori;

- Por otra parte, el sentido de sus luchas depende del desarrollo evolutivo inexorable de la historia;

- Por último, la política es el espacio preciso donde se dirimen los conflictos, como lucha de intereses.

La Constitución Política de 1991 reconoció por primera vez que Colombia es un Estado pluriétnico y multicultural, razón por la que se consagraron derechos especialísimos para los grupos étnicos diferenciados, entre los que se cuentan las comunidades indígenas. En tal sentido, los pueblos indígenas, además de ser titulares de los derechos que se reconocen a la totalidad de la población colombiana, gozamos de derechos especiales tales como el derecho a tener territorios colectivos, a nuestra cultura, cosmovisión, autonomía, jurisdicción y gobierno propios. También gozamos de los derechos consagrados en el Acuerdo 169 de la OIT, adoptado como legislación interna mediante la Ley 21 de 1991, instrumento internacional que obliga al Estado a brindar especial atención a la promoción y garantía de los derechos de estas comunidades, a consultarles toda decisión o política pública, legislativa y de desarrollo que de alguna manera nos afecte, y a respetar y hacer efectiva la autonomía de nuestros pueblos.

Este marco normativo ha sido complementado a través de reiterada jurisprudencia emitida por la Corte Constitucional, en la que se ha defendido y consolidado la autonomía y los derechos especiales de las comunidades indígenas. "Mandato libertad para la madre tierra".

Se presentan dos lógicas para analizar lo que las dos columnas nos exponen: lo cultural como referente y lo constitucional como marco de visibilización. Lo cultural definiría ese horizonte que valide el tema de las subjetividades como idea de dimensión simbólica de la construcción social que plantea el movimiento indígena desde prácticas, simbologías y discursos que constituyen el sujeto colectivo mismo; Lo constitucional es ese nuevo pacto para imaginar una nación, construirla como un lugar de encuentro y reconocimiento del otro, una noción de estado pluriétnico y multicultural, según la Constitución de 1991.

A propósito de la cuestión de sí mismo y del otro (para pensarlo desde las adscripciones y prácticas culturales), se plantea la discusión y se propone pensar e indagar el tema a través de la noción de un proyecto colectivo (Delgado, 1999). “Movimiento social indígena”, significa una experiencia en y con un tiempo social propio, elaborada desde el sujeto indígena. Si pensamos el tema de las mingas, los mandatos y la organización misma emergente a través de los proyectos comunitarios, "se trata más bien, de verdaderas nuevas formas de etnicidad, ya no basadas, como hasta entonces, en vínculos religiosos, idiomáticos, territoriales o histórico-tradicionales, sino mucho más, en parámetros estéticos y escenográficos compartidos en redes comunicacionales en común y en la apropiación del tiempo y del espacio por medio de un conjunto de estrategias de ritualización permanentemente activadas. Estas nuevas formas debemos considerarlas como pistas para pensar que todos esos actos son elaboraciones de subjetividad e intersubjetividad, y que "no se funda en un concierto entre conciencias sino experiencias, y en cuyo seno la codificación de las apariencias parece desempeñar un pedal nodal”. Es quizás, reconocer que hay unas estrategias que podemos interrogar, pues lo que se pensaría es que son las experiencias de lo cotidiano lo que excita la experiencia de un estar en movilidad relativa que reinventa la noción de espacio-tiempo socialrelacional y con ello el sujeto mismo, el colectivo mismo y la noción de comunidad, trascienden desde allí, ya no solo como un concepto o categoría, sino como un grupo social con opciones y posibilidades visibles y legitimas de actuar cultural y políticamente. 
JOHN GREGORY BELALCÁZAR VALENCIA

DETRÁS DE LOS MANDATOS Y LA MINGA INDÍGENA: ENTRE ACTOS Y PALABRAS... -PROFUNDAS RAZONESMAYORES PROPÓSITOS (UN ENCUENTRO CON UNA FORMA DE ACCIÖN COLECTIVA)

\section{REFERENCIAS}

Congreso indígena y popular (2004). El Mandato indígena y popular de la minga por la vida, la justicia, la alegría, la libertad y la autonomía. Recuperado de http://www.nasaacin.org/mandato indigena_popular.htm .

Delgado, M. (1999). Ciudad líquida, ciudad interrumpida. Medellín, Colombia: Universidad de Antioquia.

Foucault, M. (1991). El sujeto y el poder. Bogotá, Colombia: Carpediem.
García, A. (2008). Historia y sociedad. Revista Universidad Nacional de Colombia, 14, 175230. Medellín, Colombia: Universidad Nacional.

Melluci, A. (2001). Vivencia y convivencia, teoría social para una era de la información. Madrid, España: Trotta.

Torres, A. (1997). Movimientos sociales y organización popular. Bogotá, Colombia: UNAD. 